\title{
Paraplegia
}

\section{Acute Spinal Cord Injuries and the Incidence of Clinically Occurring Thromboembolic Disease}

\author{
W. P. Waring, MS, MD, ${ }^{1,2}$ R. S. Karunas, $M P H^{1}$ \\ ${ }^{1}$ Department of Physical Medicine and Rehabilitation, University of Michigan, Ann \\ Arbor, Michigan 48109, ${ }^{2}$ Rehabilitation Medicine Service, Veterans Administration \\ Medical Center Ann Arbor, Michigan, 48105, USA.
}

\section{Summary}

$A$ detailed analysis was undertaken to study the incidence of deep vein thrombosis $(D V T)$, pulmonary embolism (PE), and death during the initial hospitalisation after traumatic spinal cord injury (SCI). The National Spinal Cord Injury Statistical Center supplied data on 1419 subjects with acute injuries hospitalised between October 1, 1986 and $\mathcal{F}$ une 9, 1989. The incidence of PE was $4 \cdot 6 \%$ (4.3\% for paraplegia and $4 \cdot 8 \%$ for quadriplegia) and $14.5 \%$ for DVT (15.9\% for paraplegia and $12.5 \%$ for quadriplegia). Fifty two patients (3.7\%) died during their initial hospitalisation. Age, gender, and quadriplegia were not statistically significantly correlated with the development of DVT, while motor complete lesion was a better predictor of DVT than a complete lesion. The highest incidence of DVT was $22.9 \%$ in patients with motor complete paraplegia, while the lowest incidence was $9.3 \%$ in patients with motor incomplete quadriplegia. The only significant predictor for PE was age. Mortality was associated with increased age, PE, quadriplegia, and complete lesions. The highest incidence of death was $14.0 \%$ in patients $\geq 40$ years of age with quadriplegia and the lowest incidence of death was $0.37 \%$ in patients $<40$ years of age with paraplegia. This study emphasises the need for careful analysis and detailed stratification when designing or interpreting SCI research with DVT, PE, and mortality. Completeness of lesion, age, and category of impairment, whether quadriplegia or paraplegia, are appropriate strata to select.

Correspondence to: W. P. Waring, University of Michigan Medical Center, 1500 E. Medical Center Drive, Room 1D204C, University Hospital, Ann Arbor, Michigan, 48109, USA.

This study was supported in part by Grant G008535130 from the National Institute of Disability and Rehabilitation Research (NIDRR), Department of Education, Washington DC, USA.

Collaborating Model Spinal Cord Injury Systems sponsored by NIDRR that contributed data for this study include: University of Alabama at Birmingham Spinal Cord Injury Care System; Regional SCI Care System of Southern California; Rocky Mountain Regional SCI System; Georgia Regional SCI System; University of Michigan Model SCI Care System; Midwest Regional SCI Care System; New England Regional SCI System; Southeastern Michigan SCI System; New York Regional SCI System; Rochester Regional SCI System; Regional SCI System of Delaware Valley; Texas Regional SCI System; Virginia Regional SCI System. 
Key words: Spinal cord injury; Complication; Death; Thrombosis; Pulmonary embolism.

Risk factors for the development of thromboembolic disease for patients with acute spinal cord injuries include venous stasis due to the underlying paralysis, trauma, hypercoagulability, and immobilisation (Myllynen et al., 1987; Hachen et al., 1974). The occurrence of clinically apparent deep vein thromboses (DVT) after acute spinal cord injuries have been reported to occur with a $10-20 \%$ incidence, and the incidence of pulmonary embolism (PE) has been reported to be $5 \%$ (Berczeller and Bezkor, 1986; Young et al., 1982; Guttmann, 1976). Studies using screening tests for all acute spinal cord injury patients have reported a much higher incidence of DVT, even 100\% in some reports (Myllynen, et al., 1985; Todd et al., 1976). Berczeller and Bezkor have stated that DVT is more common in quadriplegia than paraplegia and is more common in patients with neurologically complete motorsensory lesions (Berczeller and Bezkor, 1986). Guttmann reported that DVT does not occur in children and young adults, but it is more common in females (Guttmann, 1976). Perkash stated that the level of injury and age has no striking correlation with thromboembolism (Perkash et al., 1978).

In 1982 Young et al. reported the incidence of selected major medical complications during the initial medical and rehabilitation period for 1615 patients treated in the Regional Spinal Cord Injury Systems (1973-1981). The incidence of phlebitis/thrombosis was $15 \%$ for patients classified as paraplegic and $14 \%$ for quadriplegics. The incidence of pulmonary embolism was $4 \%$ for the paraplegic group and 5\% for the quadriplegic group (Young et al., 1982). Walsh and Tribe reported that of 500 patients from the United Kingdom, 13.2\% developed phlebothrombosis and/or pulmonary embolism and complete injuries had a higher incidence than incomplete injuries (16.5\% vs. 9\%) (Walsh and Tribe, 1965). They also commented that the majority of cases with fatal pulmonary emboli had occurred without obvious signs of leg oedema or leg swelling.

Difficulties encountered in interpreting the published studies on DVT and PE with spinal cord injuries, are small samples and inconsistent stratification. In addition, the methods of diagnosing DVT or PE are not always clearly described, DVT and PE are sometimes lumped together, and results and interpretations of statistical analysis are often either not reported or simply not performed.

The purpose of this study is to update the experience of the Model Regional Spinal Cord Injury Systems as reported by Young et al., by focusing upon the occurrence of DVT and PE with acute spinal cord injuries.

\section{Methods}

At the request of the authors, the National Spinal Cord Injury Statistical Center (University of Albama at Birmingham), provided data on patients with the diagnosis of acute spinal cord injury admitted to a Model SCI System after October 1, 1986 and before June 9, 1989. Variables included age at time of injury, gender, neurological level of injury at admission and discharge, diagnosis of DVT and PE, 
diagnostic procedures used with treated cases of DVT and PE, death, cause of death, and total days hospitalised. Data was available for the initial medical and rehabilitation admission and 1 year follow-up. Neurological levels were determined according to the American Spinal Injury Association Standards for Neurological Classification of Spinal Cord Injuries. (ASIA, 1989). Data included classification at admission by Frankel grades: $\mathrm{A}=$ motor sensory complete; $\mathrm{B}=$ sensory incomplete and motor complete; $\mathrm{C}=$ nonfunction motor return, and $\mathrm{D}=$ functional motor recovery. Patients were also classified by categories of neurological impairment at admission: paraplegia-complete; paraplegia-incomplete; paraplegia—minimal deficit; quadriplegia-complete; quadriplegia—incomplete; and quadriplegia—minimal deficit.

\section{Statistical analysis}

Continuous variables are reported as a mean \pm one standard error of the mean. Relative risks and their $95 \%$ confidence intervals were calculated using dEPID, a microcomputer program for stratified and standardised analysis (Sullivan and Foster, 1987). Logistic regression modelling was done on the Michigan Interactive Data Analysis System (Fox and Guire, 1976). Comparison of total days hospitalised and ages were analysed with an independent sample Student's t-test. A MantelHaenszel Chi square test was performed to compare the incidence of PE and DVT in this study of Young's 1982 report.

\section{Results}

The average age of the 1419 subjects was $33 \cdot 0 \pm 0 \cdot 44$ years. Eighty one per cent of the subjects were male. The average length of the initial hospitalisation (includes medical/surgical stabilisation and rehabilitation) was $95 \cdot 7 \pm 1.63$ days. Data was available for 886 of the subjects 1 year after the onset of spinal cord injury. Forty nine per cent of the population were classified as paraplegic. Stratification by Frankel grades at admission as column percentages is as follows:

$\begin{array}{cccc}\text { Frankel Grade } & \text { Paraplegia } & \text { Quadriplegia } & \text { Total } \\ \text { A } & 53 \cdot 5 \% & 36 \cdot 5 \% & 43 \cdot 8 \% \\ \text { B } & 12 \cdot 4 \% & 17 \cdot 9 \% & 14 \cdot 9 \% \\ \text { C } & 15 \cdot 1 \% & 19 \cdot 2 \% & 16 \cdot 9 \% \\ \text { D } & 18 \cdot 8 \% & 26 \cdot 0 \% & 23 \cdot 5 \% \\ \text { Unknown } & 0 \cdot 2 \% & 0 \cdot 4 \% & 0 \cdot 9 \%\end{array}$

At the time of injury, the subjects less than the age of 40 years, when compared to those 40 years or older had a higher proportion of paraplegic cases $(53.5 \%$ vs. $38.6 \%)$ and complete injuries, Frankel A (48.6\% vs. $31 \cdot 9 \%)$. Of the patients classified as Frankel A at admission, $95.9 \%$ were classified as Frankel A or B at discharge, while the patients admitted as Frankel B, 69.4\% were classified as Frankel A or B at discharge. Compared to the male subjects, the female subjects were older $(35.9 \pm 0.59$ vs. $32.3 \pm 0.92$ years $)$ and had fewer complete injuries $(38 \cdot 7 \%$ vs. $45 \cdot 7 \%)$.

During the subjects' initial hospitalisation the incidence of PE was $4 \cdot 6 \%$ (4.3\% for paraplegia and $4.8 \%$ for quadriplegia) and the incidence of DVT was $14 \cdot 5 \%$ 
( $15.9 \%$ for paraplegia and $12.5 \%$ for quadriplegia). There was no statistical difference for the incidence of PE $(p=0.545)$ and DVT $(p=0.103)$ stratified by paraplegia and quadriplegia in this study compared to Young's 1982 report.

The mean age of patients with DVT did not differ significantly from the age of those without DVT $(31.9 \pm 1.02$ vs. $33.2 \pm 0.48$ years, $p>0.3)$. However patients with a PE were significantly older than patients without PE $(37 \cdot 7 \pm 2 \cdot 40$ vs. $32.8 \pm 0.44$ years, $p<0.02$ ). Diagnostic procedures used for treated cases of DVT included venography (40\%); different combinations of non-invasive (impedance plethysmography, doppler, and I-125 labelled fibrinogen uptake) methods (35\%); venography and non-invasive methods (13\%), and nonspecific methods (12\%). Diagnostic procedures used for treated cases of PE included ventilation-perfusion scans (53\%); pulmonary angiogram (21\%); ventilationperfusion scan and pulmonary angiogram (14\%); and non-specific methods (12\%).

Twelve per cent of the 199 patients with a DVT also had a PE diagnosed; $38 \cdot 5 \%$ of the 65 subjects with a PE also had a DVT. There were no cases of PE during the first year after discharge and there were 14 cases $(1 \cdot 6 \%)$ of DVT. Half of the DVT occurring after discharge occurred in patients with a DVT diagnosed during their initial hospitalisation.

Contrasting Guttmann's statement that thromboembolic disease does not occur in children and young adults, there were 46 patients younger than 15 years and there were six $(13.0 \%)$ cases of DVT and no cases of PE. In light of this small sample size of children, no further analysis was performed.

Fifty two patients $(3 \cdot 7 \%)$ died during their initial hospitalisation. The average age at injury of the patients who died during their acute hospitalisation was $58 \cdot 4 \pm 3 \cdot 18$ years compared to $32 \cdot 0 \pm 0.41$ years for the survivors $(p<0.001)$. Thirty seven of the 52 deaths $(71 \cdot 2 \%)$ occurred in patients over the age of 40 . Only 12 patients had PE listed as a cause of death and 6 of these cases had PE listed only as a post-mortem diagnosis. Among the subjects dying, $10.9 \%$ had a previously diagnosed DVT and $15 \cdot 4 \%$ had a previously diagnosed PE; conversely, $2 \cdot 4 \%$ of patients with a DVT died and $12 \cdot 3 \%$ of patients with a PE died.

The average total days hospitalised for all patients discharged alive was $98.0 \pm 1.65$ days. There was a statistically significant increase in the total days hospitalised for surviving patients with a DVT $(116 \cdot 2 \pm 4 \cdot 75$ days vs. $94 \cdot 9 \pm 1 \cdot 74$, $\mathrm{p}<0.001)$ or a PE $(114.5 \pm 7.88$ days vs. $97.2 \pm 1.68, \mathrm{p}<0.05)$.

Risk factors for developing a DVT, PE, or dying are listed in Table I. Each stratum's risk factor listed in Table I is compared to the rest of sample without the risk factor. This table shows that females were slightly less at risk for DVT than males, and Frankel A patients were at a higher risk of developing DVT than the group of Frankel B, C, and D patients. It also shows that patients with a DVT had a significantly higher risk of developing PE than those without DVT, and that those with PE were at a significantly higher risk of death than those without PE. Another group with significantly higher risk of dying was quadriplegic patients when compared to paraplegic patients.

Logistic regression (Table II) revealed that age, gender, and quadriplegia did not significantly contribute to the equation for the development of DVT. Motor complete lesion in combination with paraplegia, age, and gender predicted the probability of DVT better than complete lesion in the same combination. Age was the only significant logistic derived predictor for PE when it was used separately or 
Table I Risk factors analysis for DVT, PE and death

\begin{tabular}{|c|c|c|c|c|}
\hline Risk factor & $N^{\star}$ & Incidence $^{\star}$ & Risk ratio & $\begin{array}{c}95 \% \\
\text { Confidence intervals }\end{array}$ \\
\hline \multicolumn{5}{|l|}{$D V T$} \\
\hline Quadriplegia & $715 / 675$ & $12 \cdot 5 \% / 15 \cdot 9 \%$ & $0 \cdot 79$ & $0.61-1.02$ \\
\hline Frankel's A & $621 / 779$ & $17 \cdot 7 \% / 11 \cdot 0 \%$ & $1 \cdot 61$ & $1 \cdot 23-2 \cdot 09$ \\
\hline Age $<20$ years & $236 / 1183$ & $14 \cdot 4 \% / 14 \cdot 0 \%$ & $1 \cdot 03$ & $0.73-1.45$ \\
\hline Female & $274 / 1145$ & $9 \cdot 9 \% / 14 \cdot 0 \%$ & 0.66 & $0.45-0.96$ \\
\hline \multicolumn{5}{|l|}{$P E$} \\
\hline Quadriplegia & $715 / 675$ & $4 \cdot 8 \% / 4 \cdot 3 \%$ & $1 \cdot 11$ & $0 \cdot 68-1 \cdot 80$ \\
\hline Frankel's A & $621 / 790$ & $5 \cdot 0 \% / 4 \cdot 2 \%$ & $1 \cdot 20$ & $0.74-1.93$ \\
\hline Age $<20$ years & $236 / 1183$ & $3 \cdot 0 \% / 5 \cdot 4 \%$ & 0.55 & $0 \cdot 26-1 \cdot 20$ \\
\hline Female & $274 / 1145$ & $3 \cdot 7 \% / 4 \cdot 8 \%$ & $0 \cdot 76$ & $0 \cdot 39-1 \cdot 47$ \\
\hline DVT & $199 / 1220$ & $12 \cdot 6 \% / 3 \cdot 4 \%$ & $3 \cdot 83$ & $2 \cdot 38-6 \cdot 17$ \\
\hline \multicolumn{5}{|l|}{ Death } \\
\hline Quadriplegia & $715 / 675$ & $6 \cdot 2 \% / 1 \cdot 0 \%$ & $5 \cdot 93$ & $2 \cdot 69-13 \cdot 1$ \\
\hline Frankel's A & $621 / 790$ & $4 \cdot 7 \% / 2 \cdot 9 \%$ & $1 \cdot 60$ & $0 \cdot 94-2 \cdot 74$ \\
\hline Age $<20$ years & $236 / 1183$ & $0 \cdot 85 \% / 4 \cdot 2 \%$ & $0 \cdot 20$ & $0.05-0.82$ \\
\hline Female & $274 / 1145$ & $4 \cdot 7 \% / 3 \cdot 4 \%$ & $1 \cdot 39$ & $0 \cdot 75-2 \cdot 57$ \\
\hline DVT & $199 / 1220$ & $2 \cdot 58 \% / 3 \cdot 85 \%$ & 0.65 & $0 \cdot 26-162$ \\
\hline $\mathrm{PE}$ & $65 / 1345$ & $12 \cdot 3 \% / 3 \cdot 25 \%$ & $3 \cdot 79$ & $1 \cdot 86-7 \cdot 71$ \\
\hline
\end{tabular}

$\star$ Number or incidence of patients with risk factor listed first, then number or incidence of patients without risk factor is listed.

Table II Logistic regression analysis of risk factors for DVT and PE

\begin{tabular}{lcccc}
\hline & Coefficient & Std Error & $\mathrm{X}^{2}$ & $\mathrm{p}$ \\
\hline Full model estimate & & & -1 & $<0.001$ \\
DVT $^{\star}$ & 3.29 & 0.45 & 54.4 & $<0.001$ \\
Frankel's A + B $_{\text {Quadriplegia }}$ & 0.61 & 0.17 & 12.3 & $<0.001$ \\
Age & 0.23 & 0.16 & 2.04 & $>0.10$ \\
Gender & -0.0003 & 0.005 & 0.003 & $>0.8$ \\
Full model estimate & 0.21 & 0.11 & 3.60 & $>0.05$ \\
PE & & & & 0.039 \\
Frankel's A + B & 4.62 & 0.73 & 40.6 & $<0.001$ \\
Quadriplegia & 0.50 & 0.29 & 3.08 & $>0.05$ \\
Age & -0.44 & 0.27 & 0.27 & $>0.8$ \\
Gender & 0.21 & 0.007 & 8.14 & $<0.005$ \\
Full model estimate & 0.15 & 0.18 & 0.68 & $>0.25$ \\
Death & & & & $<0.001$ \\
DVT & 8.38 & 1.27 & 44.0 & $<0.001$ \\
PE & -0.34 & 0.54 & 0.40 & $>0.5$ \\
Frankel A & 1.34 & 0.51 & 7.06 & $<0.01$ \\
Quadriplegia & 1.83 & 0.37 & 23.9 & $<0.001$ \\
Age & -1.73 & 0.44 & 15.3 & $<0.001$ \\
Gender & 0.08 & 0.009 & 76.3 & $<0.001$ \\
& -0.068 & 0.11 & 0.12 & $>0.7$ \\
\hline
\end{tabular}

^Dependent variable

$\star \star$ Overall significance of combined independent variables based on -2 log liklihood ratio of the difference of the marginal and full model 
in combination with other dependent variables. Logistic derived predictors of death included age, PE, quadriplegia, and complete neurological lesions.

Table III lists risk ratios for DVT, PE, and death as suggested by the logistic regression modelling. This table shows that comparing quadriplegia and paraplegia with the same Frankel grades, the differences in the incidence of DVT is diminished, while stratification by Frankel motor complete grades shows difference within the paraplegia and quadriplegia groups. The incidence of DVT for patients discharged with motor complete Frankel grades (17.6\%) was not

Table III Risk factor analysis suggested by logistic regression

\begin{tabular}{|c|c|c|c|c|c|}
\hline Groups & Strata & $\mathbf{N}$ & Incidence & $\begin{array}{l}\text { Risk } \\
\text { ratio }\end{array}$ & $\begin{array}{c}95 \% \\
\text { Confidence } \\
\text { intervals }\end{array}$ \\
\hline \multicolumn{6}{|l|}{$D V T$} \\
\hline \multicolumn{6}{|l|}{ Frankel $\mathrm{A}+\mathrm{B}$ vs } \\
\hline Frankel C + D & All & $834 / 573$ & $16 \cdot 9 \% / 9 \cdot 9 \%$ & $1 \cdot 71$ & $1 \cdot 28-2 \cdot 27$ \\
\hline Paraplegia vs Quadriplegia & Frankel A + B & $445 / 389$ & $22 \cdot 9 \% / 14 \cdot 9 \%$ & $1 \cdot 25$ & $0 \cdot 92-1 \cdot 70$ \\
\hline Paraplegia vs Quadriplegia & Frankel C + D & $229 / 323$ & $10 \cdot 0 \% / 9 \cdot 3 \%$ & $1 \cdot 08$ & $0 \cdot 65-1 \cdot 81$ \\
\hline \multicolumn{6}{|l|}{ Frankel $A+B$ vs } \\
\hline Frankel C + D & Para & $445 / 229$ & $18 \cdot 7 \% / 10 \cdot 0 \%$ & $1 \cdot 86$ & $1 \cdot 20-2 \cdot 86$ \\
\hline \multicolumn{6}{|l|}{ Frankel $\mathbf{A}+\mathbf{B}$ vs } \\
\hline Frankel C + D & Quad & $389 / 323$ & $14 \cdot 9 \% / 9 \cdot 3 \%$ & $1 \cdot 61$ & $1 \cdot 06-2 \cdot 43$ \\
\hline \multicolumn{6}{|l|}{$P E$} \\
\hline $\begin{array}{l}\text { Age } \geq 40 \text { years vs } \\
<40 \text { years }\end{array}$ & All & $372 / 1047$ & $6 \cdot 7 \% / 3 \cdot 8 \%$ & $1 \cdot 76$ & $1 \cdot 08-2 \cdot 86$ \\
\hline \multicolumn{6}{|l|}{ Death } \\
\hline $\begin{array}{l}\text { Age } \geq 40 \text { years vs } \\
\quad<40 \text { years }\end{array}$ & All & $372 / 1047$ & $9 \cdot 95 \% / 1 \cdot 4 \%$ & $6 \cdot 94$ & $3 \cdot 86-12 \cdot 5$ \\
\hline Quadriplegia vs paraplegia & $<40$ years & $493 / 536$ & $2 \cdot 6 \% / 0 \cdot 37 \%$ & $7 \cdot 07$ & $1 \cdot 60-31 \cdot 2$ \\
\hline $\begin{array}{l}\text { Quadriplegia vs paraplegia } \\
\geq 40 \text { years vs }\end{array}$ & $\geq 40$ years & $222 / 139$ & $14 \cdot 0 \% / 3 \cdot 6 \%$ & $3 \cdot 88$ & $1 \cdot 55-9 \cdot 75$ \\
\hline $\begin{aligned} & <40 \text { years } \\
\geq & 40 \text { years vs }\end{aligned}$ & Paraplegia & $139 / 536$ & $3 \cdot 6 \% / 0 \cdot 37 \%$ & $9 \cdot 64$ & $1 \cdot 89-49 \cdot 2$ \\
\hline$<40$ years & Quadriplegia & $222 / 493$ & $14 \cdot 0 \% / 2 \cdot 64 \%$ & $5 \cdot 30$ & $2 \cdot 83-9 \cdot 92$ \\
\hline Frankel A vs & & & & & \\
\hline Frankel $B, C$, and D & All & $834 / 585$ & $3 \cdot 96 / 3 \cdot 25 \%$ & $1 \cdot 60$ & $0 \cdot 94-2 \cdot 74$ \\
\hline
\end{tabular}

Table IV Logistic derived incidence of death and PE by age at injury ${ }^{\star}$

\begin{tabular}{lcc}
\hline Age & Death & PE \\
$1-10$ & $0 \cdot 25 \%$ & $2 \cdot 87 \%$ \\
$11-20$ & $0 \cdot 50 \%$ & $3 \cdot 35 \%$ \\
$21-30$ & $1 \cdot 00 \%$ & $3 \cdot 91 \%$ \\
$31-40$ & $2 \cdot 00 \%$ & $4 \cdot 55 \%$ \\
$41-50$ & $3 \cdot 94 \%$ & $5 \cdot 30 \%$ \\
$51-60$ & $7 \cdot 64 \%$ & $6 \cdot 16 \%$ \\
$61-70$ & $14 \cdot 3 \%$ & $7 \cdot 16 \%$ \\
$71-80$ & $25 \cdot 1 \%$ & $8 \cdot 29 \%$ \\
$81-90$ & $40 \cdot 3 \%$ & $9 \cdot 60 \%$ \\
$91-100$ & $57 \cdot 6 \%$ & $11 \cdot 1 \%$ \\
\hline
\end{tabular}

ॠMidpoint of each interval used for calculation with the formulae $\operatorname{Pr}($ death $\mid$ age $)=1 / 1+\exp \left(6.343-0.07^{\star}\right.$ age $)$ and $\operatorname{Pr}(\mathrm{PE} \mid$ age $)=1 / 1+\exp \left(3.603-0.016^{\star}\right.$ age $)$ 
significantly different when compared to the incidence of DVT (16.9\%) for patients admitted with motor complete Frankel grades. Table III illustrates how the incidence of death varies with stratification by age, paraplegia, and quadriplegia. An alternative method of presenting the incidence of PE and death by age is to use logistic regression to calculate risk proportions. Table IV illustrates the logistic calculated increase of PE and death by age.

\section{Discussion}

Any discussion of DVT, PE, and death in patients with spinal cord injuries during the initial rehabilitation period must begin with an understanding of the population being studied. By definition the patients in Model Spinal Cord Injury Systems have traumatic injuries and this excludes other causes of spinal cord injury such as cancer or tuberculosis of the spine. Analysis of the population in this study revealed that a higher proportion of patients with paraplegia had complete lesions compared to patients with quadriplegia, and younger patients had a higher proportion of paraplegia. These different relationships of Frankel grades, proportion of quadriplegia, and age were also reported by Young et al. in 1982 .

The higher incidence of DVT with paraplegia in this study is contrary to the statement of Berczeller and Bezkor that DVT is more common in quadriplegia. Our findings support the stratification by motor complete injuries (Frankel A and B) to explain the difference in the incidence of DVT when comparing paraplegia and quadriplegia. If the major underlying factors for the development of DVT are paralysis, immobilisation, and trauma, the completeness of paralysis varies and is one factor that can be stratified by Frankel grades. Patients with Frankel grades A or $\mathrm{B}$ at admission tend not to have motor recovery of paralysed muscles. Motor recovery rarely occurs in Frankel A patients and the prognosis for motor recovery in Frankel B patients is guarded, while Frankel grades C and D rarely regress to complete motor lesions (Young et al., 1982; Maynard et al., 1979).

Although it was not statistically significant, the paraplegic patients had a higher incidence of DVT compared to the quadriplegic patients either as totals or as stratified by Frankel grades. The higher incidence of DVT with paraplegia raises a question about the role of spasticity in improving venous stasis and decreasing risk for DVT; paraplegia may be associated with a flaccid paralysis, while spasticity is almost always seen with quadriplegia. Spasticity is less commonly treated in patients with paraplegia (Maynard et al., 1989). However, the possible correlation of spasticity and DVT cannot be answered by this study since the presence of spasticity is not a variable collected by the Model Spinal Cord Injury Systems.

We found no significant differences in the risk for DVT among younger patients. Women do not have a higher risk for DVT as suggested by Guttmann and their lower incidence of DVT can be partially explained by a lower proportion of complete injuries.

The finding that the majority of the cases of PE (61.5\%) were made without a diagnosis of DVT agrees with Walsh and Tribe's observation (Walsh and Tribe, 1965). This finding runs contrary to the expectation that PE should be associated with the incidence of DVT, but this descrepancy can be explained by the fact that the lack of pain can make the diagnosis of DVT difficult especially for pelvic thrombosis. The only significant predictor for PE in this study was age and the 
incidence of DVT was not associated with age. A hypothesis to explain the singular association of PE with age is that older patients are more at risk to become symptomatic because of underlying cardiopulmonary disease while PE may be asymptomatic in younger patients with healthy lungs and hearts. The large discrepancy in the incidence of DVT during hospitalisation compared to the incidence in the post-discharge period $(14.5 \%$ vs. $1 \cdot 6 \%)$ suggests the resolution of risks factors after the initial medical-surgical stabilisation period.

The increased mortality with older patients, patients with quadriplegia, complete lesions, and the diagnosis of PE was expected. The significance of these confounders emphasises the need for detailed analysis in studies that compare mortality among different spinal cord injury populations.

DVT and PE remain significant medical problems in the Model Spinal Cord Injury Systems in terms of frequency, morbidity, and increased length of hospitalisation. We did not show any differences in the incidence of DVT and PE compared to the experience of the Model Spinal Cord Injury Systems in the preceding decade, although it would be difficult to assess the role of improved methods to diagnose these complications.

In conclusion age, gender, and quadriplegia were not statistically significantly correlated with the development of DVT, while motor complete lesion was a better predictor of DVT than complete lesions. The highest incidence of DVT was $22.9 \%$ in patients with motor complete paraplegia, while the lowest incidence was $9 \cdot 3 \%$ in patients with motor incomplete quadriplegia. The only significant predictor for PE was age. Mortality was associated with increased age, PE, quadriplegia, and complete lesions. The highest incidence of death was $14.0 \%$ in patients $\geq 40$ years of age with quadriplegia and the lowest incidence of death was $0.37 \%$ in patients $<40$ years of age with paraplegia. These differences in incidence and in the predictors for DVT, PE, and death emphasise the need for careful analysis and detailed stratification when designing or interpreting spinal cord injury research with DVT, PE, and mortality.

\section{References}

ASIA American Spinal Injury Assocition (ASIA) 1989, 250 East Superior Street, Room 619 Chicago, Illinois.

BerCzeller PH, Bezkor MF 1986 Medical Complication of quadriplegia. Year Book Medical Publishers, Inc., Chicago, page 117.

Fox E, GuIRE K 1976 Documentation for MIDAS (Michigan Interactive Data Analysis System). University of Michigan, Ann Arbor.

GuTTMANN L 1976 Spinal cord injuries: Comprehensive management and research. Blackwell Scientific Publications, Oxford, page 197.

HaChen HJ, Rossier AB, Bouvier CA, Ritschard J 1974 Deficiency within the extrinsic prothrombin activator system in patients with acute spinal cord injury. Paraplegia 12:132-138.

Maynard FM, Reynolds GG, Fountain S, Wilmot C, Hamilton R 1979 Neurologic prognosis after traumatic quadriplegia. $\mathcal{F}$ Neurosurg 50:611-616.

MAYNARD FM, KARUNAS RS, WARING WP 1989 Epidemiology of spasticity following traumatic spinal cord injury. Archives of Physical Medicine and Rehabilitation, in press, 1990.

Myllynen P, Kammonen M, RokKanen P, et al. 1987 The blood F VIII:Ag/F VIII:C ratio as an early indicator of deep venous thrombosis during post-traumatic immobilization. Journal of Trauma 27 3:287-290.

Myllynen P, Kammonen M, Rokkanen P, Bostman O, Lalla M, LaAsonen E 1985 Deep venous thrombosis and pulmonary emoblism in patients with acute spinal cord injury: a comparison with nonparalyzed patients immobilized to spinal fractures. Foumal of Trauma 25 6:541-543. 
Perkash A, Prakash V, Perkash I 1978 Experience with the management of thromboembolism in patients with spinal cord injuries: Part I. Incidence, diagnosis, and role of some risk factors. Paraplegia 16:322-331.

SUllivan KM, FosTER DA 1987 dEPID: A program for stratified and standardized analysis. Version 2.1, Division of Nutrition, Centers for Disease Control, 1600 Clifton Road, Atlanta, Georgia.

TODD JW, FrisBIE JH, Rossier AB, et al., 1976 Deep venous thrombosis in acute spinal cord injury: a comparison of I-125 fibrinogen leg scanning, impedance plethysmography and venography. Paraplegia 14 1:50-57.

WALSH JJ, TRIBE C 1965 Phlebo-thrombosis and pulmonary embolism in paraplegia. Paraplegia 3:209-213.

Young JS, Burns PE, Bowen AM, McCutchen R 1982 Spinal cord statistics: experience of the regional spinal cord injury systems. Phoenix Good Samaritan Medical Center. 